\title{
Causes of Cracks on Structures in Ngara-Tanzania
}

\author{
Fikiri Fredrick Magafu, Wu Li \\ Faculty of Engineering, China University of Geosciences, Wuhan, China \\ E-mail: fikirimagafu@yahoo.co.uk,lwu@cug.edu.cn \\ Received August 19, 2010; revised October 22, 2010; accepted November 3, 2010
}

\begin{abstract}
Development of macro and micro cracks on plastered walls and floors have been studied at different sites under site investigation whereby building inspections, construction history, engineering properties of soil and building surroundings assessment were conducted. We did revision of structural calculations and laboratory experiment to find out the source of cracks. Micro and macro cracks have no structural problems on the structure so long as the developed cracks are within the serviceability limit state [1]. There are two main causes of cracks in the structure that are structural and nonstructural sources [2]. The first task was to identify whether the source of cracks are structural or non structural. During site investigation the modes of crack formation, depth and length of crack, crack patterns and direction were studied at different sites in Ngara. Theoretical calculations of crack width and particles size distribution of sand from three main sources were analyzed after performing both sieve analysis and decantation tests. In depth site investigation, literature review and laboratory tests result showed that the causes of cracks are nonstructural and all three reliable sources of sand in Ngara contain more quantities of fines than that specified in BS 882. This paper is looking for the causes of cracks on structures and recommending further research on new idea of using simple technology and low cost methods that is affordable by both the government of Tanzania and local community of Ngara to overcome the problem of structures that develop micro and macro cracks.
\end{abstract}

Keywords: Macro Cracks, Micro Cracks, Lime Stabilized Cement-Sand Mortar, Silt and Clay Soils

\section{Introduction}

Ngara district council is implementing different projects to meet development goals that include construction of roads, bridges, culverts, classrooms, dispensaries, teacher's houses, health centers and hospitals. The funds used in these projects are disbursed from central government of Tanzania as part of fulfilling her obligation to meet millennium development goals as set up by UN - general assembly [3].

In 2001 Ngara started to implement Primary Education Development Programme (PEDP) and District Rural Development Programme (DRDP) whereby a total of 600 classrooms and 30 teachers' houses were constructed [4]. In 2005 Ngara started to implement Secondary Education Development Project (SEDP) in which new secondary schools were constructed and increased the number from 5 in 2005 to 26 secondary schools in 2009. In 2008 the district started to implement a ten years programme of Primary Health Development Programme (MMAM) whereby in first five years, 35 new dispensaries will be constructed, 3 hospitals will be rehabilitated,
13 new health centers and 88 new minor theatres will be constructed [5] .

The quality of the completed buildings during construction were checked by the local council authority engineer's office and met the specified quality but later or during construction they started to develop massive cracks on plastering and floors [6]. Poor performances in terms of early cracks and disintegration of constructed floors and plastering have been a big subject among politicians and Ngara society in general.

Extensive site investigation was carried out, and literature review was done to analyze the source of problem and to find preliminary solution. It was concluded that the cracks were caused by nonstructural sources. Intensive investigation was done to identify exactly sources. It was likely that poor workmanship and the use of substandard construction materials were the sources of problem. Since constructions were carried out by different contractors and all faced the same problem, then effort was made to analyze the sources of sand in the district. Laboratory tests carried out on three main sources of 
sand in Ngara proved beyond doubt that all sand contains fine particles $(d=0.0075 \mathrm{~mm})$ more than the specified quantity by BS 882 .

\section{Investigation Methodology and Procedures}

\subsection{Site Selection Procedure}

Since many structures have been constructed by different contractors and are in different locations within the district, a statistical random procedure based on the principles of mathematics was used to choose samples [7]. The variables were assumed to be normally distributed in the population (all structures). The following construction sites were selected for investigation:

1) Rusumo Secondary School (Benaco area) and Kafua Primary School.

2) K. 9 Secondary School and Kabulanzwili Primary School.

3) Shyunga Secondary School and Ntobeye Village Store.

4) Mukubu Primary School, Keza Secondary and Kibogora Secondary Schools.

5) Kirushya Secondary School.

6) Kirushya Dispensary and Nyamiyaga Hospital.

7) Munganza Dispensary and Ngeze Primary School.

\subsection{Site Investigation Procedures}

Site investigations involved the study on the patterns and mode, width, location and direction of cracks, depth of crack opening, formation of air pockets under plastering or flooring and strength of used cement sand mortar. Visual inspection was deployed in the determination of pattern of crack formation, direction of cracks and general assessment of nearby surroundings like availability of trees, uncontrolled flowing water etc. Measuring instruments like digital depth micrometer (Type D as manufactured by SHARPFINE of China) was used to determine the depth and width of cracks. The compressive strength of concrete was measured by digital rebound hammer (Schmidt model W-D-2000) while for plastering and sand-cement floor screed were measured by Schmidt Pendulum hammer type $P$.

The determination of foundation movement and engineering properties of soil were also studied. Leveling at 2 meters interval of the buildings were taken using Full Automatic Laser Level machine with a fixed datum at one corner of the respective building under consideration.

\subsection{Experimental Procedures for Materials Used in Construction}

There are three sources of sand in Ngara district. Sand samples were taken to laboratory for investigation as per BS 1377:Part 2:1990. Sieve analysis and decantation test were performed to get engineering properties of the sand. Cement was supplied from three manufacturers and all used the same standard as per BS 12:1996.

\section{Experimental Results}

\subsection{Safety of the Buildings}

All inspected buildings had sound strength; walls were vertical with a small diversion of $\pm 2 \mathrm{~mm}$ per meter. The buildings are single storey with maximum height of between 3.5 to 4 meters at gable side. The wall thickness was $230 \mathrm{~mm}$ without plastering.

\subsection{Site Examination and Surrounding Area}

- The Soil characteristics in the district are composed of gravel soil and rocks having bearing capacity of not less than $670 \mathrm{KN} / \mathrm{M}^{3}$ and the substructure had a sound strength to transfer loads.

- The pattern and mode of cracks were like map (alligator skin). Maximum depth of cracks was $23 \mathrm{~mm}$ and width less than $0.3 \mathrm{~mm}$. There were no specific cracks direction.

- No made up ground around all the buildings. All structures were constructed on natural ground. No earthquake or landslide history.

- Water from roofs is properly drained, no flooding history, no big trees within 10 meters from the buildings.

- There is no big variation in temperature and humidity. The recorded temperature within past 10 years shows minimum temperature of $17^{\circ} \mathrm{Cand}$ maximum of $31^{\circ} \mathrm{C}$. The area has two seasons in a year namely dry season with temperature range of $20^{\circ} \mathrm{C}$ to $31^{\circ} \mathrm{C}$ and rainy season with temperature range of $17^{\circ} \mathrm{C}$ to $27^{\circ} \mathrm{C}$.

- The strength of concrete in all structural elements was sound with minimum compressive strength of 20 $\mathrm{N} / \mathrm{mm}^{2}$ and maximum strength of $23 \mathrm{~N} / \mathrm{mm}^{2}$ while plastering had minimum compressive strength of $0.6 \mathrm{~N} / \mathrm{mm}^{2}$ and Maximum of $1 \mathrm{~N} / \mathrm{mm}^{2}$.

\subsection{Checking for Movement}

No differential settlement was noted during leveling. There may be only possibility of uniformly settlement with estimated total maximum settlement of $5 \mathrm{~cm}$ to some buildings. No heave of soil around the foundation. No horizontal movement was noted due to nature of area (plain area). No movement of cracks was noted hence, they are static cracks. 


\subsection{History of the Structures and Notation of Damage}

- The local authority of Ngara that owns the buildings and other structures under considerations gave us all needed history about the buildings including technical drawings.

- Cracks on the plastered wall were visible about two weeks later after finishing plastering and were repaired by using crack filler before painting.

- Roof structures were examined including its construction and support. The roofs were properly supported.

- Design calculations were reviewed and proved to be correct.

- Notations of damage were taken on drawings.

\subsection{Materials Used during Plastering}

Since cement is manufactured and supplied under specific condition, the attention was given to the sand. Samples from three main sources of sand in Ngara were taken to laboratory for detailed investigation. The following were the results:

\section{A: KABULANZWILI SAND.}

Decantation test and sieve analysis showed that $25 \%$ of the sand is composed of silt or clay. The Atterberg limits showed that sand has PI of 20 and shrinkage limit of $15 \%$.

\section{B: RULENGE SAND.}

Decantation test and sieve analysis showed that $18.5 \%$ of the sand is composed of silt or clay. The Atterberg limits showed that sand has PI of 11 and shrinkage limit of $10 \%$

\section{C: RUSUMO SAND.}

Decantation test and sieve analysis showed that $12 \%$ of the sand is composed of silt or clay. The Atterberg limits showed that sand has PI of 10 and shrinkage limit of $7 \%$.

\section{Discussion}

The structures were found to be structurally safe for use and source of cracks were found to be nonstructural. All foundations (natural and artificial), walls and roof had required strength as per design requirements. The minimum compressive strength of plaster is within allowable limit [8] and since the cracks were within plastered layer and the construction history revealed that cracks started after plastering of walls and screeding of floors then poor workmanship and local supplied materials can be a possible source of cracks. Weather may also contribute to the formation of these cracks but its contribution is very negligible to be discussed.
Crack width are within allowable serviceability limit state of $0.3 \mathrm{~mm}$ [9] but because structures are loosing performance due to water penetration and poor appearance then BS 8007 can be used to limit the width of cracks to between $0.1 \mathrm{~mm}$ and $0.2 \mathrm{~mm}$.

The total amount of silt and clay found in all three sources of sand are generally higher as compared to specified amount in BS 882 that limits it at 4\%. Sand having higher plasticity Index greater than 6 are not recommended for cement use due to having greater surface area than sand which increases amount of water required for mix and thus reducing strength of the concrete or mortar [10]. Clay soil has the tendency of forming a film on the particles of sand which, not only prevents the adhesion of cement to the sand particles but also retards the setting of cement thus increasing drying shrinkage.

Cracks patterns and mode [11] showed that there is high value of dry shrinkage rate for both plasters and floor screed and this can be due to higher plasticity Index in the sand.

\section{Conclusion}

Based on extensive background of similar researches, results of this research and experience of past performance, it can be concluded that the source of cracks in Ngara buildings is the presence of high quantity of fines in the sand.

\section{Recommendations}

Based on the literature reviews, laboratory results, application of theories of chemical changes and results from researches of similar nature we hereby recommend that:

1) Existing buildings.

a) For interior walls, cracks can be repaired by using thin coat of Singida gypsum powder mixed with ordinary Portland cement at a ratio of 1:4 (cement gypsum) after recoating the wall with the same thin coat of finish material (sand cement mortar). The gypsum manufacturer's instruction should be observed, or

b) Make use of an elastomeric paint coating. These coatings stretch and flex with the crack and have proven to work well in covering cracks. Elastomeric coatings will change the surface texture of the wall and tend to have a matted look when applied to a mil thickness that will perform as intended. Vapor permeability is another concern. Elastomeric coatings can bubble and blister if moisture gets trapped under the coating. The final concern is future recoating. Most elastomerics have limited options for recoating [12].

c) For exterior wall, recoat the wall from architectural break to architectural break with the same finish material but sand should be washed and be free from clays. 
2) New constructions and future research.

a) Sand should be cleaned and washed by water before use in construction of structures.

b) Further research on the use of lime stabilized cement sand mortar should be done.

\section{Acknowledgements}

This research was funded by Chinese Government Scholarship Council.

\section{References}

[1] A. H. Allen, "Reinforced Concrete Design to BS 8110-Simply Explained," E. \& F. N. SPON, New York, 1988, pp. 58-63.

[2] A. Ryan, "Causes of Cracks in the Plaster along Exterior Walls of Home," 2009. http://ezinearticles.com/?Causes -of-Cracks-in-the-Plaster-Along-Exterior-Walls-of-the-H ome\&id=2259999

[3] United Nations, Millennium Development Goals. http: //www. undp.org/mdg/basics.shtml

[4] Ngara District Council, Department of Education Progress Report, 2009, p. 53.
[5] Ministry of Health and Welfare. www.parliament.go.tz/ bunge/parl_question

[6] Ngara District Council Authority, Works Department, 2008. www.ngaradc.com

[7] L. L. Sharon, "Sampling: Design and Analysis," Duxbury Press, Pacific Grove, 1999, pp. 23-43.

[8] R. S. Boynton and K. A. Gutschick, "Strength Consideration in Mortar and Masonry," Masonry Mortar Technical Notes \# 2, 1964, p. 6.

[9] British Standard Code: BS 8110-2, 2010.

[10] P. N. Khanna, "Indian Practical Civil Engineers' Handbook," Engineers' Publishers, New Delhi, 2005, pp. 8/119-8/120.

[11] United States, Office of Archeology and Historic Preservation, Technical Preservation Services Division, "The Preservation of Historic Architecture-The US Government's Official Guidelines for Preserving Historic Homes," pp. 145-215.

[12] C. C. Roberts, "Evaluating cracks in Buildings," C. Roberts Consulting Engineers Inc., Rochelle, http//www. croberts.com, p. 56. 